\title{
Ankara İli Kızılcahamam İlçesi’nde Taşkın Ötelenmesi Yöntemlerinin Performans Analizleri
}

\author{
${ }^{1}$ Metin SARIGÖL ve ${ }^{* 2}$ Ömer YÜKSEK \\ ${ }^{1}$ Erzincan Üzümlü Meslek Yüksekokulu, Erzincan Binali Yıldırım Üniversitesi, Erzincan, Türkiye \\ *22 Karadeniz Teknik Üniversitesi, İnşat Mühendisliği Bölümü, Trabzon, Türkiye
}

\section{Özet}

Bu çalışmada, Ankara İli Kızılcahamam İlçesi'nde meydana gelen taşkına ait 120,90 km² alana sahip D12A242 nolu Akım Gözlem İstasyonu'nda (AGİ) ve bu AGI'nun 2,061 km mansabındaki D12A126 nolu AGI'nda gözlenen birer saat aralıklı hidrograf verileri kullanılarak, ölçülen değerler ile hidrolojik ve hidrolik modellerin sonuçları karşılaştırılmıştır. Çalışmada hidrolojik modeller olarak Muskingum ve SCS; hidrolik modeller olarak da Kinematik Dalga, Muskingum-Cunge ve Dinamik yöntemler uygulanmıştır. Modellerin ölçülen değerlere uygunluğu; ölçülen ve modellerden hesaplanan değerler arasındaki Ortalama Mutlak Hata $(\mathrm{OMH})$, Hataların Ortalama Karekökü (HOK) ve Belirlilik Katsayısı $\left(\mathrm{R}^{2}\right)$ değerleri hesaplanarak belirlenmiş ve yöntemlerin performansları irdelenerek hangi yöntemin daha iyi sonuç verdiği değerlendirilmiştir. Çalı̧̧ma sonunda, Dinamik Yöntemin en iyi tahmini verdiği, Muskingum ,Kinematik ve SCS Yöntemlerinin tahminlerinin de kabul edilebilecek düzeyde olduğu, Muskingum-Cunge Yönteminin ise biraz daha hatalı tahmin verdiği belirlenmiştir.

Anahtar Kelimeler: Taşkın Ötelemesi, Hidrolik Model, Hidrolojik Model.

\section{Comparison of the Performances of Flood Routing Methods in Ankara Province Kızılcahamam District}

\begin{abstract}
In this study, by using one-hourly flood hydrograph values in Ankara Province Kizılcahamam District Kizilcahamam, for the the D12A242 Stream Observation Station (SOG), which has 120,90 km² area and for the D12A126 SOG, which is located at 2,061km downstream of this AGI, the measured values and the results of hydrological and hydraulic models were compared. Muskingum and SCS as hydrological models and Kinematic Wave, Muskingum-Cunge and Dynamic methods have been applied as hydraulic models. Suitability of models were determined by using Mean Absolute Error (MAE), Root Mean Square Error (RMSE) and Determination Coefficient $\left(\mathrm{R}^{2}\right)$ values between the measured and calculated hydrograph values from the models. At the end of the study, it has been determined that SCS Method gives the best estimation, Muskingum-Cunge and Muskingum Methods predictions are acceptable, and Kinematic Method and Dynamic Method give incorrect estimates.
\end{abstract}

Keywords: Flood Routing, Hydrological Methods, Hydraulic Methods.

\footnotetext{
* Sorumlu Yazar: Adres: Erzincan Üzümlü Meslek Yüksekokulu, Erzincan Binali Yıldırım Üniversitesi, Üzümlü, Erzincan, TÜRKIYE. E-mail address: metinsarigol@hotmail.com
} 


\section{Giriş}

Taşkın, bir yağış sonucunda akışa geçen suyun akarsu yatağı dışına taşmasıdır. Bu akış yağmur veya kar erimesinden oluşabilir [1;2]. Şiddetli yağmur veya kar erimesinden meydana gelen akışlarda genellikle büyük debiler oluşur [3]. Akarsu havzalarında debi akarsu yatak kapasitesini aşarak dışarı taşar. Yine bu tür durumlarda ova olan bölgelerde ise taşkın geniş alanlara yayılır ve zararlara sebep olur [4; 5]. Taşkın çalışmaları, suyun zararlarından korunmak için su kaynaklarının geliştirilmesi ve önlem alınması açısından büyük öneme sahiptir [6]. Taşkınlar, yerleşim yerleri ve tarım arazilerinin zarar görmesine, yol, köprü ve baraj gibi yapıların yıkılması sebep olabilir [4]. $\mathrm{Bu}$ gibi zararların önlenmesi veya en aza indirilmesi için baraj, sel kapanı, sedde gibi yapılar yapılmakta, ayrıca akarsu yatağında da çeşitli düzenlemeler yapılarak gerekli önlemler alınabilmektedir [7; 8; 9]. Bu tür çalışmalara yüksek meblağda paralar harcanması, olası afetlerin meydana getireceği zararlardan çok daha ekonomik olmakta ve bu ekonomik fayda ile çok kısa sürede geri kazanılmaktadır $[10 ; 11 ; 12]$. Bir taşkın dalgası akarsu yatağı veya biriktirme haznesinden geçerek mansaba doğru ilerlerken debisinde ve hızında değişime uğramaktadır. Bu değişim, taşkın dalgasının geçtiği bölgenin fiziksel ve topoğrafik özelliklerine (suyu geri tutma) bağlı olarak değişmektedir. Bu nedenle, taşkın dalgasının geçişi sırasında debi zamanla azalmakta ve zamana göre bir miktar geciktiği için bu hareket " Taşkın Ötelenmesi'” olarak adlandırılır [12]. Başka bir deyişle taşkın ötelenmesi, taşkın dalgasının bir kanal veya hazne boyunca herhangi bir noktadaki debi değerlerinin zamana bağlı olarak değişiminin hesaplanmasıdır [13]. Taşkın ötelenmesinin hesabı için geliştirilen yöntemler, esas olarak hidrolojik ve hidrolik yöntemler olarak iki ana gruba ayrılmaktadır. Bu yöntemlerden hangilerinin gerçeğe daha yakın değer verdiğinin belirlenmesi için uygulanabilecek en iyi yöntem, arazide yapılmış ölçümler sonucu elde edilen hidrograflar ile yöntemlerin hesapladığı hidrografların karşılaştırılmasıdır. Bu çalışmada, Anakara İli Kızılcahamam İlçesi'nde meydana gelen taşkına ait $120,90 \mathrm{~km}^{2}$ alana sahip D12A242 nolu Akım Gözlem İstasyonu'nda (AGI) ve bu AGİ'nun 2,061 km mansabındaki D12A126 nolu AGİnda gözlenen birer saat aralıklı hidrograf verileri kullanılarak, ölçülen değerler ile hidrolojik ve hidrolik modellerin sonuçları karşılaştırılmıştır. Çalışmada hidrolojik modeller olarak Muskingum ve SCS; hidrolik modeller olarak da Kinematik Dalga, Muskingum-Cunge ve Dinamik yöntemler uygulanmıştır. Modellerin ölçülen değerlere uygunluğu; ölçülen ve modellerden hesaplanan değerler arasındaki Ortalama Mutlak Hata (OMH), Hataların Ortalama Karekökü (HOK) ve Belirlilik Katsayısı $\left(\mathrm{R}^{2}\right)$ değerleri hesaplanarak belirlenmiş ve yöntemlerin performansları irdelenerek hangi yöntemin daha iyi sonuç verdiği değerlendirilmiştir.

\section{2. Çalışmanın Amacı}

Taşkın ötelenmesi, taşkın dalgasının bir kanal veya hazne boyunca herhangi bir noktadaki debi değerlerinin zamana bağlı olarak değişiminin hesaplanmasıdır. Taşkın kontrolü açısından taşkın öteleme hesaplarının pek çok faydası bulunmakta olup, bunların en önemlisi, akarsuyun belirli bir kesitteki taşkın büyüklükleri bilindiğinde, bu kesitin kilometrelerce mansabındaki bir kesitteki taşkın hidrograflarının saatlerce önceden tahmin edilebilmesi ve böylece can ve malın kurtarılması

*Corresponding author: Address: Faculty of Engineering, Department of Civil Engineering Sakarya University, 54187, Sakarya TURKEY. E-mail address: caglar@ sakarya.edu.tr, Phone: +902642955752 Fax: +902642955601 
ve taşkın zararlarının en aza indirilmesi için gerekli zamanın kazanılabilmesi ve sonuçta taşkın zararlarının azaltılmasıdır.

\section{Materyal ve Yöntem}

\subsection{Kullanılan Yöntemler}

Literatürde taşkın ötelenmesi konusunda kullanılan sayısal yöntemler genel olarak hidrolojik yöntemler ve hidrolik yöntemler olmak üzere iki gruba ayrılmaktadır [5,14].

\subsubsection{Hidrolojik Yöntemler}

Hidrolojik taşkın ötelenmesinin geniş bir kullanım alanı vardır ve mühendislik uygulamalarında da sık sık kullanılır. Esas amaç hidrolik yapıların tasarımı ve taşkın önlemlerinin alınmasında taşkın ötelenmesi yaparak taşkının hızının ve büyüklüğünün belirlenmesidir [15]. Hidrolojik yöntemler kurulurken sadece süreklilik denklemi kullanılır [16]. Akım derinliği ve debi iki bilinmeyen parametre olup, çözümü için ise bir denkleme daha ihtiyaç vardır. Bu denklem de akarsu parçasındaki biriktirme hacmi ve giren-çıkan debiler arasında bir bağıntı kurularak elde edilir. Bu yöntemde, akarsu eşit uzunlukta parçalara ayrılarak ötelenme işlemi yapılır [14;17]. En üst parçadan en alta doğru, her bir parça için bilinen giriş hidrografı kullanılarak çıkış hidrografı adım adım hesaplanır. Çıkış hidrografı bir sonraki parçanın giriş hidrografı olarak kabul edilerek hesaplar yapılır. Bu şekilde belirli zaman aralıklarında akarsuyun belirli kesitlerindeki debi bulunur. Hidrolik yöntemlere göre gerek çabuk hesap yapılması ve gerekse havzayla ilgili az bilgiye ihtiyaç duyulmasından dolayı tercih edilir. Hidrolojik yöntemler olarak Straddle-Stagger, Tatum, Muskingum ve SCS yöntemleri kullanılmaktadır. Ancak, son zamanlarda literatürde yaygın olarak kullanılmasından dolayı bu çalışmada Muskingum ve SCS yöntemleri kullanılmış ve aşağıda açıklanmıştır.

Muskingum Yöntemi: Muskingum Yöntemi 1930'lu yıllardan itibaren nehir mühendisliği uygulamalarında geniş bir şekilde kullanılmıştır [18; 19]. Bu yöntem hidrolojik yöntemlerden olup, ilk olarak 1938 yılında U.S Army Corps of Engineers ve McCarty tarafından Muskingum nehrindeki taşkınların ötelenme çalışmalarında kullanılırken geliştirilen yöntem geniş bir kulanım alanına sahip olup, akarsu ötelenme işlemlerinde çok sık kullanılır. Yöntem kurulurken süreklilik denklemi baz alınır ve dinamik etkiler ihmal edilir. Bu yöntemin temeli akarsu parçasındaki hem süreklilik, hem de depolama ve giriş, çıkış akımları arasında lineer bir ilişki olduğu kabulüne dayanır [20; 21]. Muskingum Yöntemi ile ötelenmenin temeli, akarsu parçasına süreklilik denkleminin uygulanmasına dayanır [22]. Muskingum Yöntemi az eğimden dik eğime doğru artan eğimlerde iyi sonuçlar vermekte ve yaygın olarak kullanılmaktadır [22; 23]. Muskingum Yönteminin taban eğiminin yüksek olduğu akarsularda ve hidrografın yükselme süresinin büyük olması durumunda iyi sonuç verdiği belirlenmiştir [16]. Bu yöntem basitliği sebebiyle en sık kullanılan ötelenme yöntemlerinden birisidir [12;24].

SCS Yöntemi: $\Delta \mathrm{x}$ uzunluğundaki akarsu parçası için ötelenmede kullanılan $\Delta \mathrm{t}$ zaman aralığı uygun şekilde seçilerek ötelenme işlemi yapıldığında, zaman aralığ bitimindeki y2 çıkış debisi, zaman 
aralığının başlangıcındaki $\mathrm{x}_{1}$ ve $\mathrm{y}_{1}$ debileri arasında kalmakta, buna göre ele alınan hidrografın yükselme bölgesinde $\mathrm{x}_{1}>\mathrm{y}_{2}>\mathrm{y}_{1}$, alçalma bölgesinde ise $\mathrm{x}_{1}<\mathrm{y}_{2}<\mathrm{y}_{1}$ şeklinde olur.

\subsubsection{Hidrolik Yöntemler}

Hidrolik yöntemlerde akım yerin ve zamanın bir fonksiyonu olarak hesaplanır. Süreklilik denklemine ek olarak hareket (momentum) denklemi kullanılır. Başlıca hidrolik ötelenme yöntemleri Difüzyon Dalga Yöntemi, Kinematik Dalga Yöntemi [9;17;25], Muskingum-Cunge Yöntemi [21; 23; 26] ve Dinamik Dalga Yöntemi şeklindendir. Kinematik Dalga, MuskingumCunge ve Dinamik Yöntem [27; 28; 29] ile yapılan çalışmalar literatürde yaygı̀n olarak kullanıldığından dolayı, bu çalışmada tercih edilmiş ve aşağıda açıklanmıştır.

Kinematik Dalga Yöntemi: Kinematik Dalga Yöntemi teorisi taşkın dalgası hareketini tanımlamak içinbasitleştirilmiş bir yaklaşımdır. Bu yöntemin temel varsayımı, su akımındaki kontrol hacmine etkieden sürtünme kuvvetinin akım yönündeki kuvvet ile dengelenmesidir. Kinematik yöntemin temel avantajı, dinamik denklemin çözümünden kolay olması ve hesapların sadeleştirilmesidir. Kinematik yöntemin dezavantajı ise, fiziksel geçerlilik ile yöntem çözümler arasında olan belirsizlik olup bu da denklemlerdeki sadeleştirilmenin artmasıyla artmaktadır [1;13]. Kinematik Yöntemle yapılan taşkın ötelenme hesaplarında sonuç hidrografları mesafeden etkilenmektedir [17;30]. Kinematik dalga yöntemi kabarma etkilerinin olduğu akarsularda kötü sonuçlar vermesine rağmen, Saint-Venant denklemleri ile çözümü yapılan diğer yöntemlere göre en geniş kullanımı olan yöntemlerdendir [31].

Muskingum-Cunge Yöntemi: Hareket eden taşkın dalgasının sönümlenmesine sebep olan kanalın fiziksel şartları ve akım özellikleri akımın bir fonksiyonu olarak değiştiğinden, bu yöntem doğrusal katsayılı olmayan bir yöntemdir. Muskingum-Cunge Yönteminde kanalın fiziksel özellikleri ve giriş hidrografına bağlı olarak ötelenme yapıldığından dolayı yöntem, hidrolik bir yöntem olarak görülmektedir. Muskingum-Cunge Yöntemi Saint Venant denklemlerin-deki basınç, ağırlık ve sürtünme kuvvetlerini göz önüne alıp, atalet terimlerinin ihmal edildiği difüzyon formuna dayanır. Cunge, Muskingum Yöntemini birinci dereceden difüzyon denklemi gibi sonlu fark ifadesini kullanarak geliştirmiş ve bu da Muskingum-Cunge Yöntemi olarak adlandırılmıştır. MuskingumCunge yöntemi taşkın ötelenme problemlerini çözmek için sıklıkla uygulanan etkili bir tekniktir. Bu yöntemde iki serbest parametre olup bunlar zamansal ve mekânsal olarak adlandırılır. Yöntemin doğruluğu da bu parametrelerin seçilen aralıklarına bağlıdır [2]. Muskingum-Cunge Yönteminin sonuçlarıyla teorik olarak hesaplanan pik debi ve ötelenme süresinin karşılaştırılması sonucunda, analitik ve sayısal sonuçlar arasındaki yakınlık, Muskingum-Cunge Yönteminin taşkın ötelenmede rutin uygulamalar için uygulanabilir ve doğru bir yöntem olduğunu göstermektedir [32]. Eğer bir akarsuda giren ve çıkan akım hidrografları daha önceden gözlenerek elde edilmemişse K ve a parametreleri belirlenemez. Bu durumda Muskingum denklemi x ve t sonlu farklar ağına yazılarak her kesitte hesaplanacak şekilde Muskingum-Cunge Yöntemi kullanılır [33]. Muskingum-Cunge Yönteminin hesaplamaları diğer hidrolik yöntemlere göre daha kolay olup, arazi verileri bakımından daha az bilgiye ihtiyaç duymaktadır [34]. Genel olarak, Muskingum-Cunge Yöntemi taşkın ötelenmede akarsuda yanal akım olmadığı zaman Kinematik Dalga Yönteminden daha üstün ve daha fazla tercih edilen bir yöntemdir [35].

Dinamik Yöntem: Dinamik taşkın ötelenme yöntemi başlangıç ve sınır koşullarının oluşturulması açısından uygulanması en zor yöntemlerden birisidir [36]. Zamanla değişen üniform olmayan akımların incelenmesi zordur. Taşkın sırasında akımın ana yataktan taşkın yatağına yayılması ve 
yan kollar, baraj hazneleri, köprüler ve kesit değişmesi sonucu su yüzeyinde kabarma etkilerinin oluşması problemi daha zor hale getirmektedir. Bu tür olaylar Saint-Venant denklemlerinin tüm terimlerinin göz önünde tutulması sonucu incelenebilmektedir. Ancak bu denklemlerin analitik çözümleri elde edilemediğinden, sayısal yöntemler ile çözüme gidilmektedir. Akarsu taban eğimi ve sürtünme katsayısının farklı kombinasyonları şeklinde yapılan hesaplamalarda ise Dinamik Yöntem diğer yöntemlere göre daha esnek, hızlı ve doğru sonucu bulmada etkili bir yöntemdir [29].

\subsection{Kullanılan Veriler}

Bu çalışmada, Ankara İli Kızılcahamam İlçesi’nde 05.05.2014 tarihinde meydana gelen taşkına ait $120,90 \mathrm{~km}^{2} \mathrm{~km}^{2}$ alana sahip D12A242 nolu Ak1m Gözlem İstasyonu'nda (AGİ) ve bu AGİnun 2,061km mansabındaki D12A126 nolu AGİnda gözlenen birer saat aralıklı hidrograf verileri kullanılarak, ölçülen değerler ile hidrolojik ve hidrolik modellerin sonuçları karşılaştırılmıştır. AGİ için Manning Pürüzlülük Katsayısı n $=0.073$ ve taban eğimi de $\mathrm{J}=0.024$ olarak hesaplanmıştır.

\section{Bulgular}

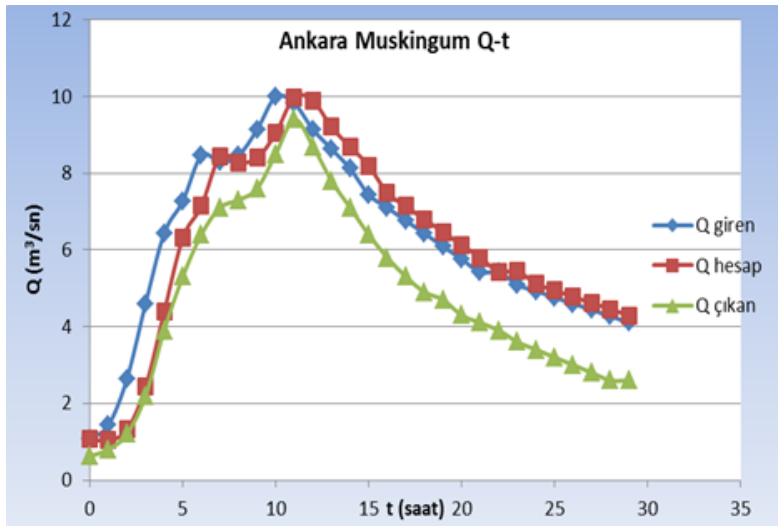

Şekil 1. AGI'nin Muskingum Yöntemine göre hesaplanmış ve ölçülmüş değerleri

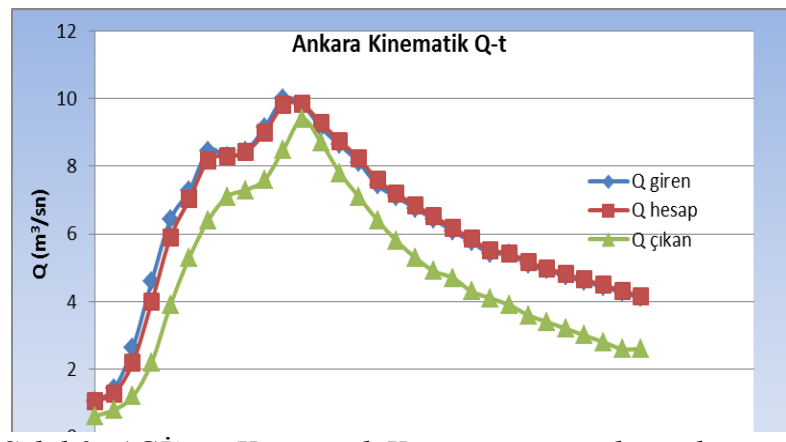

Şekil 3. AGI'nin Kinematik Yöntemine göre hesaplanmış Şı ve ölçülmüş dĕgerleri

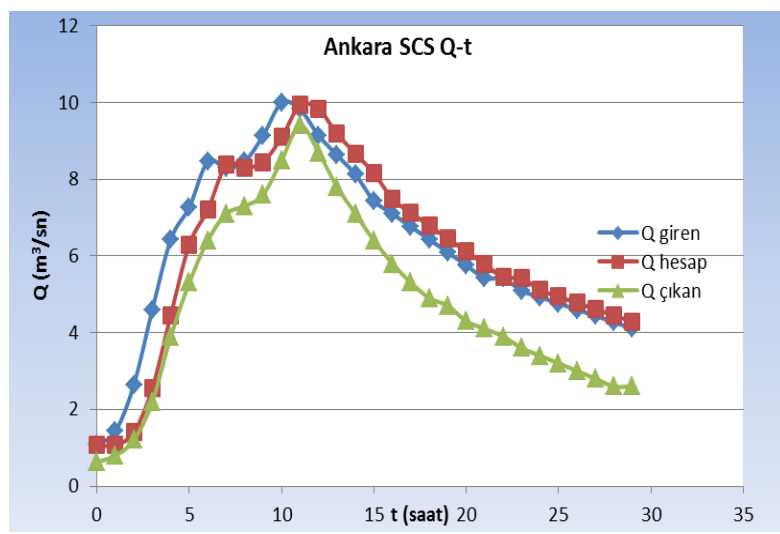

Şekil 2. AGI'nin SCS Yöntemine göre hesaplanmış ve ölçülmüş değerleri

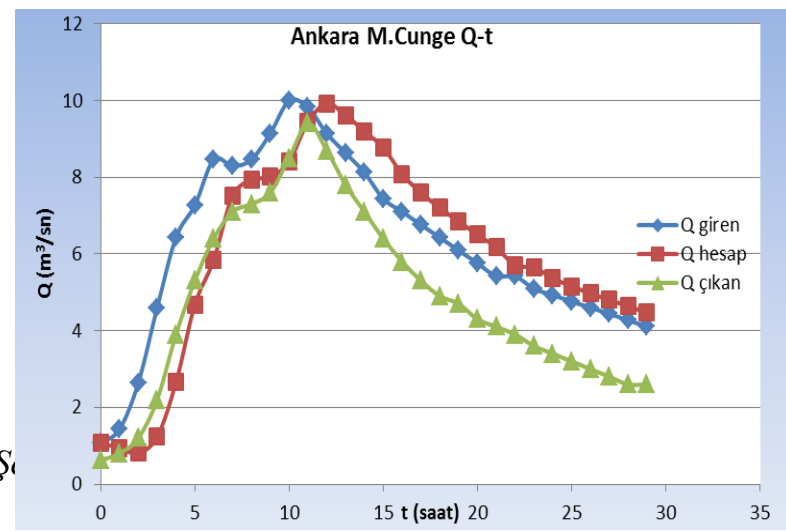




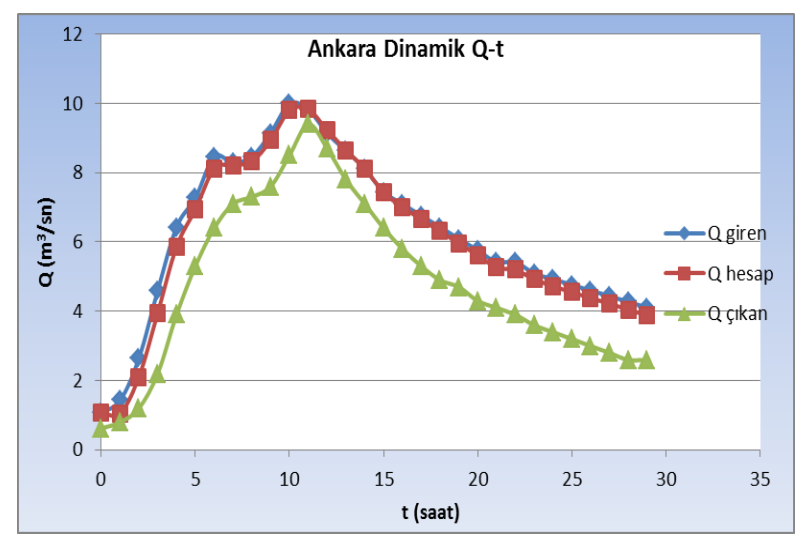

Şekil 5. AGi'nin Dinamik Yöntemine göre hesaplanmış ve ölçülmüş değerleri

Tablo 1. Ankara Taşkın Ötelenme Yöntemleri Sonuç Hata Analizi

\begin{tabular}{|l|c|c|c|c|c|}
\hline Ankara & $\begin{array}{c}\text { Muskingum } \\
\text { Yöntemi }\end{array}$ & $\begin{array}{c}\text { SCS } \\
\text { Yöntemi }\end{array}$ & $\begin{array}{c}\text { Kinematik } \\
\text { Yöntem }\end{array}$ & $\begin{array}{c}\text { Muskingum- } \\
\text { Cunge Yöntemi }\end{array}$ & $\begin{array}{c}\text { Dinamik } \\
\text { Yöntem }\end{array}$ \\
\hline HOK & 1.40 & 1.40 & 1.41 & 1.63 & 1.26 \\
\hline OMH & 1.27 & 1.28 & 1.35 & 1.41 & 1.20 \\
\hline $\mathbf{R}^{\mathbf{2}}$ & 0.94 & 0.95 & 0.97 & 0.81 & 0.97 \\
\hline
\end{tabular}

\section{Sonuçlar}

Ülkemizde meydana gelen taşkınlar hem can hem de mal kaybına sebep olmakta, bu da ülkemiz ekonomisini olumsuz yönde etkilemektedir. Bu çalışmanın amacı, bir taşkın afeti esnasında taşkının meydana geldiği yerdeki taşkın hidrografı kullanılarak, bu noktanın kilometrelerce mansabındaki bir yerdeki taşkın hidrografının saatlerce hatta günlerce önce tahmin edilmesidir.

Dinamik Yöntemin HOK ve OMH hata değerleri küçük, $\mathrm{R}^{2}$ değeri de büyük olduğundan, incelenen havzada en iyi yöntemin bu yöntem olduğu görülmüştür. Ancak Muskingum, SCS, MuskingumCunge ve Kinematik yöntemlerinin hata değerleri Dinamik Yönteme yakın olduğundan dolayı, bu yöntemlerinde uygulanabilir seviyede olduğu, Muskingum-Cunge Yönteminin ise en hatalı sonuçlar verdiği belirlenmiştir. 


\section{Kaynaklar}

[1] Akbari, G. ve Firoozi, B., 2010. Implicit and Explicit Numerical Solution of Saint-Venant Equations for Simulating Flood Wave in Natural Rivers, 5th National Congress on Civil Engineering, Ferdowsi University of Mashhad, Mashhad, Iran.

[2] Barry, D. A. ve Bajracharya, K., 1995. On The Muskingum-Cunge Flood Routing Method, Environment International, Vol. 21(5), pp. 485-490.

[3] Bayazıt, M. ve Önöz B., 2008. Taşkın ve Kuraklık Hidrolojisi, Nobel Akademik Yayıncılık, Ankara.

[4] Bayazıt, M., 1995. Hidroloji, İ.T.Ü. İnşaat Fakültesi Matbaası.

[5] Chow, V. T., Maidment, D. R. ve Mays L. W., 1988. Applied Hydrology, McGraw-Hill, Inc, USA.

[6] Çimen, M., 1995. Difüzyon Yöntemi ile Akarsu Yatağındaki Taşkınların Ötelenmesi. Yüksek Lisans Tezi, SDÜ Fen Bilimleri Enstitüsü, Isparta.

[7] Gökoğlu, F., 2000. Akarsularda Taşkın Dalgalarının Sayısal Analizi, Yüksek Lisans Tezi, YTÜ Fen Bilimler Enstitüsü, İnşaat Mühendisliği Anabilim Dalı, İstanbul.

[8] Jayyousi, F. E., 1994. Evaluation of Flood Routing Techniques for Incremental Damage Assessment, Doctor of Philosophy Dissertation, Utah State University, Utah.

[9] Karahan, H. ve Gürarslan, G., 2012. Kinematik Dalga Yaklaşımı Kullanılarak Taşkın Öteleme Problemlerinin Modellenmesi: Sütçüler Örneği, VII. Ulusal Hidroloji Kongresi.

[10] Knapp, H. V., Durgunoglu, A. ve Ortel, T. W., 1991. A Review of Rainfall-Runoff Modeling for Stormwater Management, U.S. Geological Survey, Hydrology Division, Illinois.

[11] Lee, K. T. ve Huang, P. C., 2012. Evaluating the Adequateness of Kinematic-Wave Routing for Flood Forecasting in Midstream Channel Reaches of Taiwan, Journal of Hydroinformatics, 14.4, pp: 1075-1088.

[12] Sarı̈öl, M., 2018. Taşkın Ötelenmesinde Kullanılan Bazı Hidrolojik ve Hidrolik Yöntemlerinin Performanslarının Karşılaştırılması, Karadeniz Teknik Üniversitesi, Fen Bilimleri Enstitüsü, Yayınlanmamış Doktora Tezi, Trabzon.

[13] Atalay, O., 2008. Taşkın Hidrografının Elde Edilmesiyle İlgili Yöntemlerin Karşılaştırılması, Yüksek Lisans Tezi, KÜ Fen Bilimler Enstitüsü, İnşaat Mühendisliği Anabilim Dalı, Kocaeli.

[14] Choi, C. C., 2013. Coupled Hydrologic And Hydraulic Models And Applications, Master Theses, The University of Iowa, Iowa.

[15] Tewold, M. H., 2005. Flood Routing in Ungauged Catchments Using Muskingum Model, Master Theses, University of Kwa-Zulu-Nata, Pietermaritzburg.

[16] Ülke, A., 2001. Taşkın Öteleme Metodları, Seminer I Notları, Isparta.

[17] Cheng, J. Y., 2011. Modification of Kinematic Wave Cascading Model for Low Impact Watershed Development, Doctor of Philosophy Dissertation, University of Colorado, Denver.

[18] Kundzewicz Z. W. ve Strupczewski W. G., 1982. Approximate Translation in the Muskingum Model, Hydrological Sciences Journal, Vol.27 (1), pp. 19-17.

[19] Ülke, A., 2003. Muskingum Metodu Kullanılarak Taşkın Ötelenmesi, Yüksek Lisans Tezi, SDÜ Fen Bilimler Enstitüsü, İnşaat Mühendisliği Anabilim Dalı, Isparta.

[20] Chaudhry, H. M., 2008. Open-Channel Flow Second Edition, Springer Science Business Media, LLC, 324.S, USA.

[21] Wang, G. T., Yao, C., Okoren, C. ve Chen, S. 2006. 4-Point FDF of Muskingum Method Based on The Complete St Venant Equations, Journal of Hydrology, Vol.324 (1), pp.339- 
349.

[22] Maidment, D. R., 1993. Handbook of Hydrology, McGraw-Hill, Inc. P10.1.

[23] Afzali S. H., 2016. Variable-Parameter Muskingum Model, Iranian Journal of Science and Technology, Transactions of Civil Engineering, Vol.40 (1), pp. 59-68.

[24] Tung, Y. K., 1985. River Flood Routing By Nonlinear Muskingum Method, Journal of Hydraulic Engineering, 111 (12), 1447-1460.

[25] Ogunlela, A. O. ve Kasali, M. Y., 2014. Kinematic Flood Routing of Asa River, International Journal of Engineering and Technical Research, Vol. 2 (3), pp.13- 17.

[26] Elbashir, S. T., 2011. Flood Routing in Natural Channels Using Muskingum Methods, Master Theses, Dublin Institute of Technology.

[27] Haktanir, T. ve Özmen, H., 1997. Comparison of Hydraulic and Hydrologic Routing on Three Long Reservoirs, Journal of Hydraulic Engineering, Vol.123 (2), pp.153-156.

[28] Keskin, M. E. ve Ağıralioğlu, N., 1997. A Simplified Dynamic Model for Flood Routing in Rectangular Channels, Journal of Hydrology, Vol. 202, pp. 302-314.

[29] Soentoro, E. A., 1991. Comparision of Flood Routing Methods. Master Theses, University of British Columbia, Vancouver, Canada.

[30] Soleymani, M. ve Delphi, M., 2012. Comparison of Flood Routing Models (Case Study: Maroon River, Iran), World Applied Sciences Journal Vol. 16 (5), pp: 769-775.

[31] Xia, R., 1992. Sensitivity of Flood Routing Models to Variations of Momentum Equation Coefficients and Terms, Doctor of Philosphy Dissertation, University of Illinois, Urbana.

[32] Ponce, V. M., Lohani, A. K. ve Scheyhing, C. 1996. Analytical Verification of MuskingumCunge Routing, Journal of Hydrology, Vol. 174(3-4), pp. 235-241.

[33] Özmen, H., 1999. Baraj Gölünden Taşkın Öteleme Modelleri, Doktora Tezi, ÇÜ Fen Bilimler Enstitüsü, İnşaat Mühendisliği Anabilim Dalı, Adana.

[34] Shultz, M. J., 1992. Comparison of Flood Routing Methods for Rapidly Rising Hydrograph Routed Through a very Wide Channel, Master Thesis, The University of Texas, Arlington.

[35] Hec-1, 1990. Flood Hydrograf Package, User's Manual, Hydrologic Engineering Center, U. S. Army Crops of Engineers.

[36] Chatila, J. G., 1992. Application and Comparison of Dynamic Routing Models For Unsteady Flow in Simple and Compound Channels, Master Thesis, University of Ottawa, Canada. 